\title{
Studies of left atrial pressure during cardioplegia produced by profound hypothermia using the closed chest technique
}

\author{
J. B. JOHNSTON, J. M. NIELD, G. R. PRITCHAR D, A N D \\ V. M. HERCUS \\ From the Department of Cardio-pulmonary Surgery, University of New South Wales, Sydney
}

Profound hypothermia can be induced and reversed with safety without opening the chest when a heart/lung machine is used (Woodhall, Sealy, Hall, and Floyd, 1960 ; Patterson and Ray, 1962). Blood is drained into the heart/lung machine from an external iliac vein and, after being oxygenated and cooled or warmed as the case may be, is returned to the body through an external iliac artery (Fig. 1). During cooling, ventricular fibrillation almost always occurs, but this can be reversed externally during rewarming. When the temperature is sufficiently low, it is possible to arrest the circulation completely for long

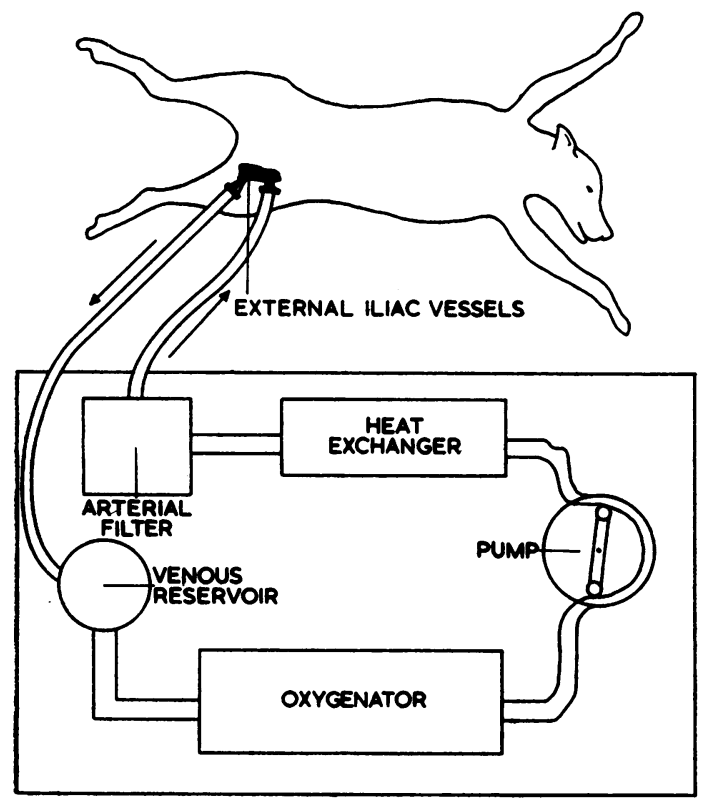

FIo. 1. Diagram of the bypass circuit used in the experiments. periods of time, e.g., at $10^{\circ}$ C. a period of 60 minutes of circulatory arrest is well tolerated. When it is possible to arrest the circulation in this way, neurosurgeons have derived considerable benefit when operating on difficult intracranial aneurysms (Patterson and Ray, 1962; Michenfelder, Kirklin, Uihlein, Svien, and MacCarty, 1964). This technique has been used successfully when operating on eight patients in this unit (Gonski, Johnston, Hercus, Rollison, and Nield, 1964).

In these operations, when the body is being cooled and rewarmed, there are long periods of cardioplegia. However, blood continues to accumulate in the left side of the heart from the bronchial circulation, and it might be anticipated that the left atrial pressure would reach dangerously high levels as the left ventricle can no longer eject its contents. This would lead to irreversible damage in the heart and lungs. In practice, however, the successful clinical results of Patterson and Michenfelder and of the present authors indicate that this cannot be so.

The studies described below were designed with the object of finding out what happens to the left atrial pressure under these conditions.

\section{METHOD}

Dogs weighing between 20 and $30 \mathrm{~kg}$. were used. General anaesthesia was induced by injecting intravenously 4 to $8 \mathrm{ml}$. of $2 \%$ thiopentone followed by $1 \mathrm{mg}$. $/ \mathrm{kg}$. suxamethonium chloride. The animal was then intubated under direct vision using the largest possible Magill's tube. Anaesthesia was maintained with oxygen-enriched air with the addition of $\frac{1}{2}$ to $1 \%$ of halothane. The gas mixture was given through a circle absorber, and the animal was placed on controlled ventilation using a Beaver Mark 2 respirator. Controlled respiration was continued until the onset 
of ventricular fibrillation and was resumed when the heart was defibrillated. The electrocardiogram was monitored. The venous pressure was monitored through the left external jugular vein and the arterial pressure through a cannula inserted into the left femoral artery. The right external iliac vesseis were then exposed. After heparinization $(3 \mathrm{mg}$. $/ \mathrm{kg}$.) the largest possible bore plastic cannula was inserted into the right external iliac vein and pushed well up into the inferior vena cava. The right external iliac artery was cannulated with a metal cannula of as large a bore as possible.

In the meantime the heart/lung machine had been primed. The essential components of the heart/lung machine are shown in Figure 1. They consist of a venous reservoir, a 23 in. rotating disc oxygenator, a roller pump of the De Bakey type, a heat exchanger, and a bubble trap (Cohen, Hercus and Ebsary, 1960). The machine was primed with $1,000 \mathrm{ml}$. of normal saline and $1,500 \mathrm{ml}$. of fresh heparinized blood, and was then connected to the two cannulae in the external iliac vessels. The operating table was raised to provide gravity drainage equivalent to 30 in., and the extracorporeal circulation was commenced.

During the standard experiment, flow rates were adjusted with the object of maintaining constant the amount of blood in the extracorporeal circuit. In other words, the same amount of blood was returned to the animal as was drained from the external iliac vein. The average flow rate in these circumstances was 50 to $60 \mathrm{ml} . / \mathrm{kg}$., equivalent to 1.3 litres $/ \mathrm{min} . / \mathrm{m}^{2}$

During the cooling and rewarming the following temperature measurements were made: blood flowing into the machine, blood flowing out of the machine, pharyngeal, oesophageal, and rectal. During rewarming, when the oesophageal temperature reached $30^{\circ} \mathrm{C}$., defibrillation was achieved, usually with one shock of 1,000 volts A.C. for $0 \cdot 1$ second applied externally. Rewarming was continued until a temperature of $35^{\circ} \mathrm{C}$. was reached, and, before bypass was discontinued, the animal was transfused to raise the venous pressure to approximately $10 \mathrm{~mm}$. $\mathrm{Hg}$. The cannulae were removed, and the effect of heparin was reversed by injecting intravenously 4.5 $\mathrm{mg}$. of hexadimethrine bromide per $\mathrm{kg}$.

\section{TECHNIQUE OF MEASUREMENT}

The left atrial pressure was measured directly using the trans-septal technique originally described by Ross (1959). The Ross needle was introduced through the right external jugular vein and directed into the right atrium under fluoroscopic control. The atrial septum was then penetrated and the catheter pushed into place. Its position in the left atrium was confirmed at the beginning and the end of each experiment by measuring the oxygen saturation of the blood which was withdrawn through the catheter.

Three different groups of animals were studied.

SERIES 1 Five animals were studied, the left atrial pressure being measured directly as above. The protocol, which has been described, was followed, and the flow rate was adjusted with the object of maintaining constant the volume of blood in the extracorporeal circuit. This is the procedure which is followed with patients, and in these circumstances the flow rate averaged $60 \mathrm{ml} . / \mathrm{kg} . / \mathrm{min}$.

SERIES 2 Three animals were studied. Exactly the same procedure was adopted as in series 1 with the exception that the flow rate was artificially increased so that it averaged $120 \mathrm{ml} . / \mathrm{kg}$. $/ \mathrm{min}$. (2.6 litres $/ \mathrm{min} . /$ $\left.\mathrm{m} .{ }^{2}\right)$. This was made possible by periodic transfusions of blood from the machine to the animal. The total volume transfused throughout an experiment averaged between 500 and $700 \mathrm{ml}$.

SERIES 3 Five animals were studied. The left atrial pressure was not measured but the animals were cooled and rewarmed as in series 1 , using a flow rate which averaged $60 \mathrm{ml} . / \mathrm{kg}$. The period of cardioplegia was greatly prolonged in this experiment. At $10^{\circ} \mathrm{C}$. the circulation was arrested for 50 minutes, and this was followed by a period of circulation lasting 10 minutes. This manœuvre was repeated a further two times so that each of these animals was subjected to a period of complete arrest of the circulation lasting two and a half hours. In each of these animals the heart was inactive in the presence of a circulation for at least one hour, and in most instances the period averaged two hours. In this series it was decided to appraise the effect of any change in the left atrial pressure by observing whether or not pulmonary oedema developed and by studying the survival of the animal.

\section{RESULTS}

RATE OF COOLING When the flow rate was $60 \mathrm{ml}$./ $\mathrm{kg}$./min., the rate of cooling and rewarming was approximately $1^{\circ} \mathrm{C}$. every two minutes. This is demonstrated in graphic form in Figure 2. It will be noted that initially the rectal temperature drops much more quickly than the temperature in the pharynx. This is due to the fact that the cooled blood from the machine circulates in the lower part of the body in the early part of the perfusion, whereas the cardiac output from the animal is going to the upper part of the body. As soon as ventricular fibrillation develops, however, the pharyngeal temperature drops very rapidly. The rate of cooling and rewarming was approximately twice as rapid when the flow rate was doubled.

LEFT ATRIAL PRESSURE The behaviour of the left atrial pressure in the animals in series 1 , where the flow rate was $60 \mathrm{ml} . / \mathrm{kg} . / \mathrm{min}$., is seen in Table $I$. 


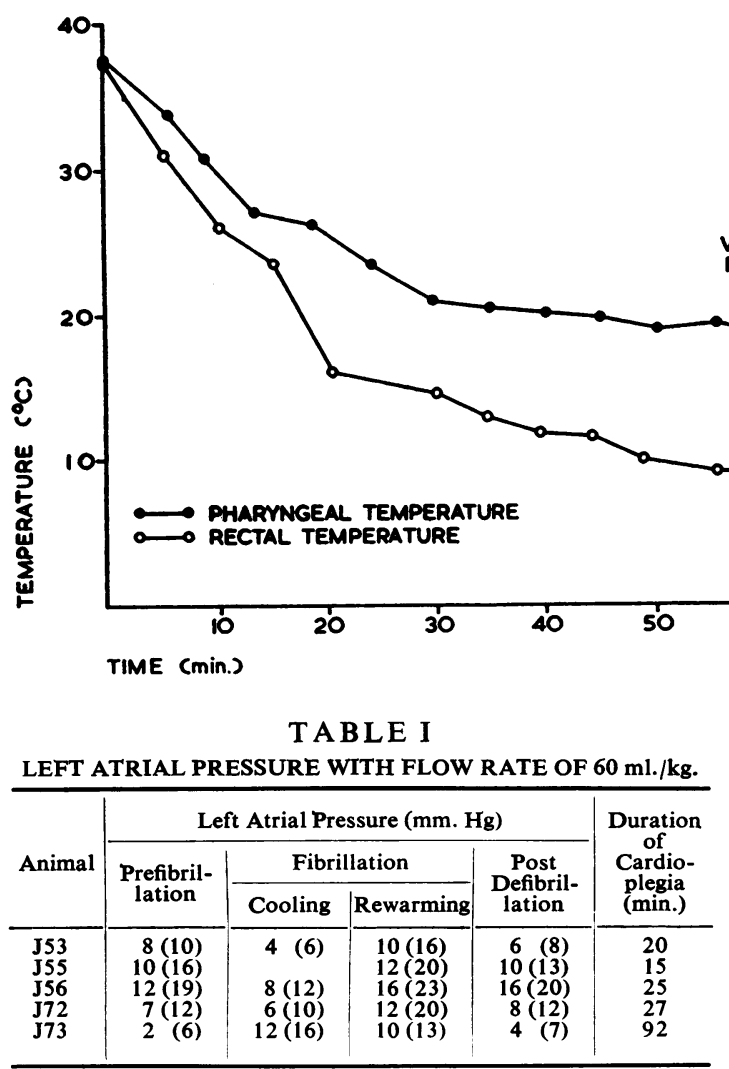

These figures represent the mean left atrial pressure and the figures in parentheses represent the peak mean pressure. It was noted that at no time did the pressure reach excessive levels although it invariably rose from the basic pre-bypass level.

Table II is a record of the left atrial pressures in the animals belonging to series 2 . In these animals the flow rate was artificially maintained by transfusion at a rate of 120 to $130 \mathrm{ml} . / \mathrm{kg}$./ min. It will be noted that during the period of ventricular fibrillation, although the left atrial pressure was higher than in series 1 , it still did not

\section{T A B LE II}

LEFT ATRIAL PRESSURE WITH FLOW RATE OF $120 \mathrm{ml}$. $\mathrm{kg}$.

\begin{tabular}{c|c|c|c|c|c}
\hline & \multicolumn{3}{|c|}{ Left Atrial Pressure (mm. Hg) } & $\begin{array}{c}\text { Duration } \\
\text { of } \\
\text { Animal }\end{array}$ \\
\cline { 2 - 5 } & $\begin{array}{c}\text { Prefibril- } \\
\text { lation }\end{array}$ & \multicolumn{2}{|c|}{ Fibrillation } & $\begin{array}{c}\text { Post } \\
\text { Defibril- } \\
\text { lation }\end{array}$ & $\begin{array}{c}\text { Cardio- } \\
\text { plegia } \\
\text { (min.) }\end{array}$ \\
\hline J75 & $9(36)$ & $15(23)$ & $18(24)$ & $4(8)$ & 43 \\
J77 & $22(40)$ & $16(20)$ & $8(10)$ & $12(16)$ & 35 \\
J78 & $22(33)$ & $10(20)$ & $18(22)$ & $7(8)$ & 35 \\
\hline
\end{tabular}

FIG. 2. Illustrating the differential cooling which occurs before ventricular fibrillation. exceed the level which can be tolerated by the heart and lungs. An interesting point which emerged was that in each instance the pressure in the left atrium before fibrillation was higher than that after the onset of fibrillation. Although the average mean pressures in this period did not reach the point at which pulmonary oedema is likely to develop, a peak mean pressure as high as $40 \mathrm{~mm}$. was noted.

The fate of the animals in series 3 is represented in Table III. Each of these animals was subjected

TABLE III

DURATION OF CARDIOPLEGIA RELATED TO

\begin{tabular}{|c|c|c|c|c|}
\hline \multirow[b]{2}{*}{ Dog } & \multicolumn{2}{|c|}{ Duration (min.) } & \multirow[b]{2}{*}{$\begin{array}{c}\text { Pulmonary } \\
\text { Oedema }\end{array}$} & \multirow[b]{2}{*}{ Fate } \\
\hline & Cardioplegia & $\begin{array}{c}\text { Cardioplegia } \\
\text { with } \\
\text { Circulation }\end{array}$ & & \\
\hline $\mathbf{J} 60$ & 211 & 61 & 一 & Lived 12 hours- \\
\hline J61 & 285 & 135 & - & $\begin{array}{l}\text { Lived } 2 \text { weeks- } \\
\text { thrombi in } \\
\text { heart }\end{array}$ \\
\hline $\begin{array}{l}\mathrm{J} 62 \\
\mathrm{~J} 63\end{array}$ & $\begin{array}{l}220 \\
280\end{array}$ & $\begin{array}{r}70 \\
130\end{array}$ & - & $\begin{array}{l}\text { Alive at } 4 \text { months } \\
\text { Lived } 4 \text { days- } \\
\text { infection }\end{array}$ \\
\hline J64 & 271 & 121 & - & $\begin{array}{l}\text { inrection } \\
\text { Lived } 15 \text { hours- } \\
\text { ? V.F. }\end{array}$ \\
\hline
\end{tabular}

to a period of circulatory arrest of two and a half hours with correspondingly prolonged periods of cardioplegia in the presence of an active circulation. All five animals regained consciousness and none developed any evidence of pulmonary oedema. Four of the animals died later but, in 
each instance, apart from $\mathrm{J} 64$, which developed ventricular fibrillation, the cause of death did not appear to be related to damage to the heart or lung.

\section{DISCUSSION}

The above studies show that when profound hypothermia was produced by the closed chest technique, using cardio-pulmonary bypass, the left atrial pressure did not rise progressively to the point where damage would occur to the heart and lungs during the period of cardioplegia. This is true when the flow rate is maintained at that level permissible by the nature of the cannulation. Even when the flow rate is artificially maintained at double this rate by periodic transfusions of blood to the animal, the left atrial pressure still remains at an acceptable level during cardioplegia.

The results of the experiments in series 3 demonstrated further that there does not seem to be a progressive rise of left atrial pressure in spite of subjecting the animal to periods of cardioplegia, with circulation, which are well beyond the limits required in clinical practice.

The explanation of this behaviour of the left atrial pressure is not immediately apparent. It is presumed that bronchial flow continues during the cooling and rewarming periods. This blood, in theory, should continue to accumulate in a closed system which is blocked on the one hand by the aortic valve and on the other by the pulmonary valve. The distensible pulmonary vessels could undoubtedly accommodate a considerable volume of blood without elevation of pressure but during the prolonged periods of cardioplegia in series 3 it would be expected that the pressure would eventually reach high levels. An explanation of the failure of the left atrial pressure to rise is that with the development of ventricular fibrillation the pulmonary valve becomes incompetent. Blood would then drain from the left atrium and the lungs into the right atrium. The right atrium in turn would be decompressed through the cannula in the inferior vena cava.

Ross, Gilbert, Sharp, and Morrow (1958) measured the left atrial pressure during total cardio-pulmonary bypass with the chest open. They found that during cardiac arrest with the animal on bypass the left atrial pressure would rise but would fall immediately if a right atriotomy was performed. Furthermore, if the pulmonary artery was then clamped, in spite of the atriotomy, the pressure would then rise again and would reach dangerous levels. A further series of experiments is being conducted to evaluate this theory and will be reported later.

The highest levels of left atrial pressure in the series of experiments conducted above occurred in those animals where the flow rate was $120 \mathrm{ml}$./ $\mathrm{kg}$. in the period before fibrillation. Furthermore, in these animals it fell when fibrillation developed. It is suggested that in these circumstances, in the period before fibrillation, although the right ventricle is able to pump blood through the lungs into the left atrium, at a certain stage in cooling the left ventricle is unable to compete with the heart/lung machine. In spite of the left ventricular contraction, the aortic valve would remain closed in these circumstances and the left atrial pressure would rise. Because of this we routinely induce ventricular fibrillation in patients on cooling when the temperature reaches $28^{\circ} \mathrm{C}$.

\section{SUMMARY}

A study has been made of the left atrial pressure during cardioplegia produced by profound hypothermia using the closed chest technique.

It is noted that with flow rates of from 60 to $120 \mathrm{ml} . / \mathrm{kg}$. the left atrial pressure does not reach dangerous levels during cardioplegia.

Before cardioplegia it is possible to raise the left atrial pressure to a dangerous level if the flow rate is maintained by the extracorporeal circuit at a level sufficient to block the cardiac output.

Prolonged cardioplegia with an active circulation does not apparently lead to progressive elevation of the left atrial pressure.

\section{REFERENCES}

Cohen, D., Hercus, V., and Ebsary, V. R. (1960). The Royal Alexandra Hospital for Children heart-lung machine. Med. J. Aust., 2, 734.

Gonski, A., Johnston, J. B., Hercus, V. M., Rollison, R. A., and Nield, J. (1964). Profound hypothermia for intracranial surgery case report. Ibid., 1, 318 .

Michenfelder, J. D., Kirklin, J. W., Uihlein, A., Svien, H. J., and MacCarty, C. S. (1964). Clinical experience with a closed-chest method of producing profound hypothermia and total circulatory arrest in neurosurgery. Ann. Surg., 159, 125.

Patterson, R. H., Jr., and Ray, B. S. (1962). Profound hypothermia for intracranial surgery. Ibid., 156, 377 .

Ross, J., Jr. (1959). Transeptal jeft heart catheterization: A new method of left atrial puncture. Ibid., 149, 395.

- Gilbert, J. W. Jr. Sharp, E. H and Morrow, A. G. (1958) Elective cardiac arrest during total body perfusion: The relationship of elevated intracardiac pressures during arrest to subsequent myocardial function and pathologic pulmonary changes. $J$. thorac. Surg., 36, 534.

Woodhall, B., Sealy, W. C., Hall, K. D., and Floyd, W. L. (1960) Craniotomy under conditions of quinidine-protected cardioplegia and profound hypothermia. Ann. Surg., 152, 37. 